\title{
Power Quality improvement in LV smart grid by using the Open UPQC device
}

\author{
G. Accetta ${ }^{1}$, G. D’Antona ${ }^{2}$, D. Della Giustina ${ }^{1}$ and R. Faranda ${ }^{2}$ \\ ${ }^{1}$ A2A Reti Elettriche SpA \\ Via Lamarmora 230, 25124 Brescia (Italy) \\ Phone number: +39 030.355.5301, e-mail: giovanni.accetta@a2a.eu, davide.dellagiustina@a2a.eu \\ ${ }^{2}$ Politecnico di Milano, Dipartimento di Energia \\ Via la Masa 34, 20156 Milano (Italy) \\ Phone number: +39 02.2399.3793, e-mail: gabriele.dantona@polimi.it, roberto.faranda@polimi.it
}

\begin{abstract}
This paper presents the application of the Open Unified Power Quality Conditioner as a tool to improve the power quality in low voltage distribution grids. This system consists of a single or three-phase AC/DC power converter installed at customer's premises and a main three-phase AC/DC power converter in the MV/LV substation. $O-U P Q C$ will be installed and tested in the city of Brescia (north of Italy) within Smart Domo Grid, a project co-funded by the Italian Ministry of Economic Development. A preliminary analysis of the power quality and the load distribution of the test area will be used as input for the design of the system.
\end{abstract}

Keywords: Power Quality, Smart Grid, Smart Domo Grid project, Open UPQC.

\section{Introduction}

The service offered by Distribution System Operators (DSOs) is characterized by regulatory pressures aimed at improving the quality of service. In the case of Italy, the Authority of Electrical Energy and Gas (AEEG) released in 2011 a new resolution [1] upgrading the target for the continuity of service (progressively reduction of the number and the length of disconnections per customer) and mandates to monitor the Power Quality (PQ) on the distribution grid starting from MV busbars in primary substation (PS), before 2015. The focus is on voltage dips. It is reasonable to believe that in the next years, a more wide spread monitoring will be required and a remuneration/penalization mechanisms for the power quality will be introduced, as is today for the continuity. At the very same time European programs, aimed at protecting the environment - such as the European "20-2020" directive [2] - are vigorously promoting and rewarding customers who install distributed generation (DG). The growing complexity, brought about by DG, will make more difficult to meet those quality of service standards. DSOs have to start immediately to analyze the PQ of their grid and to find out new tools to cope with the compensation of voltage dips in time. Some initiatives have been already launched. Among them, the Smart Domo Grid (SDG) project is co-funded by the Italian Ministry of Economic Development (Ministero dello
Sviluppo Economico) and deals with two main topics:

- Demand Response aimed at the shaving of the peak power demand in order to reduce investments for new network infrastructures and the customers' bill [3];

- the PQ improvement on the LV grid [4],[5] by means of power electronics equipment called $O-U P Q C$ (Open Unified Power Quality Conditioner) including distributed energy storage (DDES).

This project will be carried out in a real DSO environment in the city of Brescia (North of Italy).

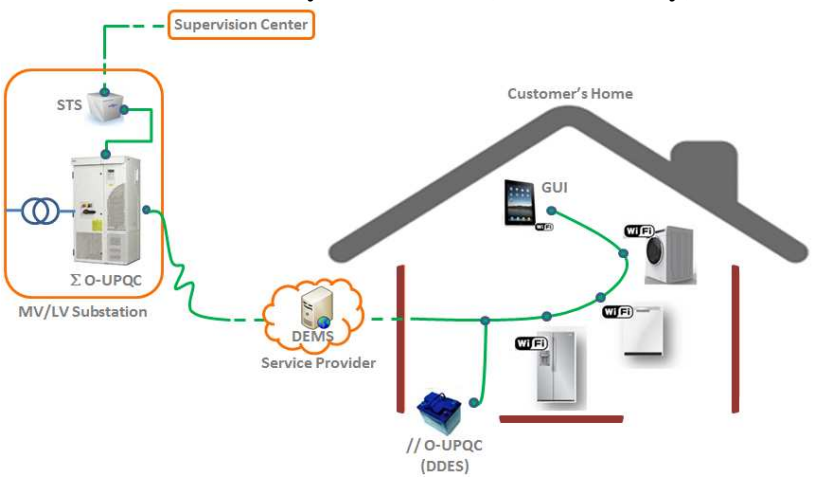

Fig. 1. SDG logical system architecture of SDG.

Fig. 1 shows the logical architecture proposed by SDG. It is a distributed intelligence system, consisting of:

- a central intelligence which supervise the entire architecture and dispatching needs of peak shaving and real-time tariff to every STS.

- an intelligent unit installed in MV/LV substations (Smart Transformer secondary Substation unit - STS), which measures the status of the grid, controls the $O-U P Q C$ and issues peak-shaving requests via a realtime tariff;

- a Domestic Energy Management System - DEMS an from a service provider, receiving the total consumption and the local generation (if any - e.g. PV plants); receiving a real-time price information; controlling smart appliances and a Domestic Energy Storage (DDES, the storage part of the // O-UPQC 
system);

Section 2 describes more in detail the $O-U P Q C$ structure the system used to improve the PQ. Section 3 and 4 reports the distribution of voltage dips in the city of Brescia and the distribution of energy delivered as a function of the contractual power for $\mathrm{LV}$ customers. Section 5 describes the limits of $O-U P Q C$ architecture in function of its size.

\section{O-UPQC description}

Concerning the PQ, SDG proposes to use an electronic device called $O-U P Q C[6]$. It consists of:

- a series electronic device installed in the MV/LV substation, called $\Sigma O-U P Q C$ unit,

- parallel units installed at the customer's home, called // O-UPQC unit, connected to a Domestic Distributed Energy Storage (DDES).

Fig. 2 shows the multi-wire power layout of the device in a three-phase, four-wire distribution network under study.

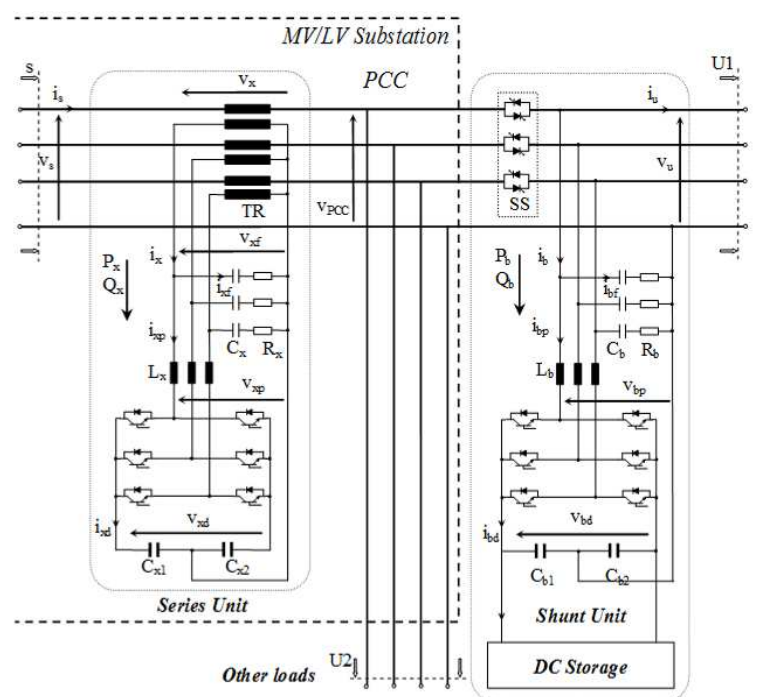

Fig. 2 - Multi-wire power diagram of the new proposed solution.

The $\Sigma O-U P Q C$ unit consists of a coupling transformer (TR), with the primary circuit connected in series with the mains line and a secondary one supplying the reversible AC/DC power converter. The output stage of the Pulse Width Modulation (PWM) voltage controlled converter contains passive $\mathrm{RC}$ shunt filters, to compensate for the harmonic currents at switching and multiple frequencies. Neglecting the active power to compensate the converter losses, the series unit is controlled to act as a purely reactive inductor when the supply voltage, $V_{S}$, is within its operation limits $\left(0.9 V_{n} \leq V_{s} \leq 1.1 V_{n}\right)$. This fact is of fundamental importance, because in this range the loads $U_{1}$ (protected) and $\mathrm{U}_{2}$ (not protected) must be supplied by the mains $95 \%$ of the time, as established by the IEEE Std. 1159 "IEEE Recommended Practice for Monitoring Electric Power Quality" and European EN50160; therefore, the storage system must not discharge itself. Outside of this range, active power can be used to compensate disturbances, in the same way as the usual series compensation devices [7], when a storage system is present.

The //O-UPQC units consist of an AC/DC power converter, similar to the one used in the $\Sigma O-U P Q C$ unit, connected to a different energy storage system and a set of static switches (SS) [8]. The parallel unit, depending on the state of the network voltage, can supply either the entire load $\mathrm{U}_{1}$ or a part of the load $\mathrm{U}_{1}$.

There are two different modes of $O-U P Q C$ operation:

- compensator: when the Point of Customer Connection (PCC) voltage is within its operation limits, the SS are closed, the series unit works as a three-phase voltage generator and the shunt units work as current generators;

- back-up: when the PCC voltage is outside of its operation limits, the SS are open, decoupling the network and the load-compensator system. Each sensitive load $U_{1}$ is supplied by its shunt unit, which acts as a sinusoidal voltage generator, using the energy stored in the storage system as an energy source.

Table I describes the main functionalities of the system.

Table I. O-UPQC functionalities

\begin{tabular}{|c|c|c|c|}
\hline \multirow{2}{*}{ Voltage } & \multicolumn{2}{|c|}{ O-UPQC actions } & \multirow{2}{*}{ Load effects } \\
\hline & $\Sigma$ unit & // unit & \\
\hline $\begin{array}{l}\text { Black-out } \\
V_{s}<0.05 V_{n}\end{array}$ & No action & $\begin{array}{c}P_{b} \text { and } \\
Q_{b} \\
\text { injection }\end{array}$ & $\begin{array}{c}U_{1} \text { supplied } \\
U_{2} \text { unsupplied }\end{array}$ \\
\hline $\begin{array}{l}\text { Deep voltage dips } \\
0.05 V_{n}<V_{s}<0.4 V_{n}\end{array}$ & No action & $\begin{array}{c}P_{b} \text { and } \\
Q_{b} \\
\text { injection }\end{array}$ & $\begin{array}{c}U_{1} \text { supplied } \\
U_{2} \text { unsupplied }\end{array}$ \\
\hline $\begin{array}{c}\text { Voltage dips } \\
0.4 V_{n}<V_{s}<0.9 V_{n}\end{array}$ & $\begin{array}{l}P_{x}{ }^{1} \text { and } Q_{x} \\
\text { injection }^{2}\end{array}$ & $\begin{array}{c}Q_{b} \\
\text { injection }\end{array}$ & $\begin{array}{l}U_{1} \text { supplied } \\
U_{2} \text { supplied }\end{array}$ \\
\hline \begin{tabular}{|c|} 
Voltage fluctuation \\
$0.9 V_{n}<V_{s}<1.1 V_{n}$ \\
\end{tabular} & $\begin{array}{c}Q_{x} \\
\text { injection }\end{array}$ & $\begin{array}{c}Q_{b} \\
\text { injection }^{3}\end{array}$ & $\begin{array}{l}\mathrm{U}_{1} \text { supplied } \\
U_{2} \text { supplied }\end{array}$ \\
\hline
\end{tabular}

${ }^{1}$ the $P_{x}$ injection is possible only for few time and if it is necessary

2 to control the voltage into PCC

${ }^{3}$ to increase the performance of $\Sigma O-U P Q C$

Information about the depth and the duration of voltage dips are primarily used to evaluate a suitable size for the $\Sigma O-U P Q C$ unit. Considering to supply $60 \%$ of the LV network power and a small storage system, $\Sigma O-U P Q C$ unit can compensate for most of the voltage dips disturbances working as a Dynamic Voltage Restore [7]. It is important to underline that considering the high power respect to the energy needs the storage can be realized fruitfully by Supercapacitors [9]-[11].

Each // O-UPQC unit is sized in relation to its supplied loads power and energetic autonomy required by the end user, protecting its sensitive load against interruptions. The function of the //O-UPQC unit is similar to that of the UPS output stage [7], but it is less expensive because it only has one conversion stage and involves less power loss. 
Section 3 and 4 describes the distribution of voltage dips and the distribution of the delivered energy versus the contractual power of residential customers needed to design the $O-U P Q C$.

\section{Analysis of voltage dips measurements}

In Fig. 3 an analysis of voltage dips distribution in ca. a thousand MV/LV substation, performed by the Electric Power Research Institute, has been reported [12]. As can be seen in Fig. 3, more than $95 \%$ of voltage dips can be compensated by injecting a voltage of up to $60 \%$ of the nominal voltage, with a maximum duration of 30 cycles.

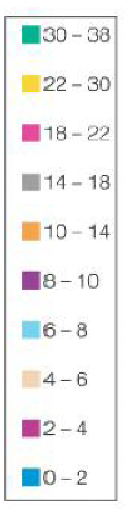

Events per Site per Year

Fig. 3 - Example of distribution of voltage disturbances reported in the EPRI event coordination chart.

In order to perform a more accurate design of the $O-U P Q C$ system, it is important to examine the distribution of the voltage dips where the system will be installed, i.e. in the city of Brescia. In this area, managed by A2A Reti Eletriche SpA, all the MV busbars in $\mathrm{HV} / \mathrm{MV}$ and MV/MV substation have been already equipped by power quality meters, since 2010. Fig. 4 shows the distribution of voltage dips as a function of duration and residual voltage ${ }^{1}$ recorded during each voltage dip, including both single and multi-phase events. In case of multi-phase events, the worst measured value is reported (the longest duration and the lower residual voltage). Data refers to year 2011.

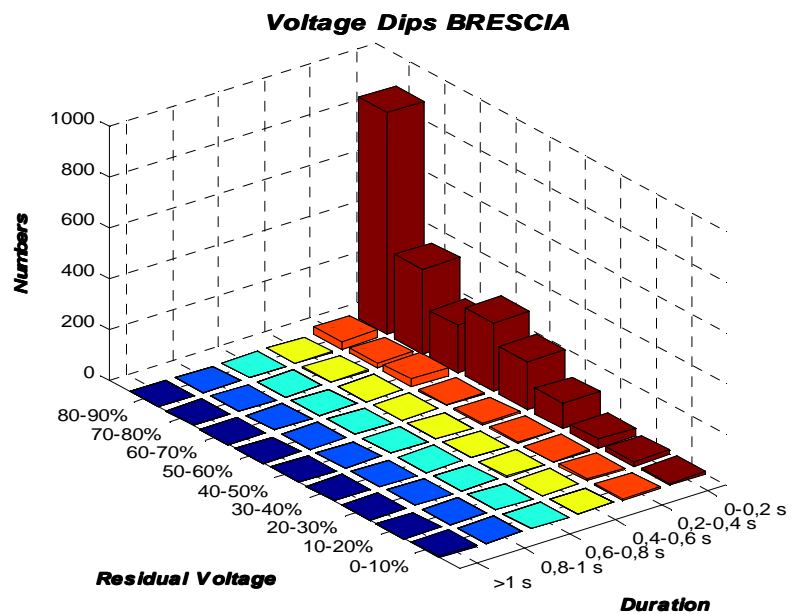

Fig. 4. Distribution of voltage dips in the city of Brescia.

\footnotetext{
${ }^{1}$ Residual voltage is the minimum value of the RMS expressed as a percentage of the reference voltage.
}

Table II reports the number of single, double and three phases voltage dips for Brescia area.

Table II. Total number of event

\begin{tabular}{l|c}
\hline \multicolumn{1}{c|}{ Type of dip } & Numbers \\
\hline single phase & 832 \\
\hline double phase & 379 \\
\hline three phase & 912 \\
\hline TOT & 2123 \\
\hline
\end{tabular}

Like Fig. 3, Fig. 4 suggests that the most of events last between 0 and $200 \mathrm{~ms}$ and in this group ca. $40 \%$ have a residual voltage dip between $80 \%$ and $90 \%$. Fig. 5 and Table III describe the voltage dip distribution of two primary substation:

- PS-VIOLINO is a $23 \mathrm{kV} / 15 \mathrm{kV}$ substation (MV/MV), it has 1 busbar and $5 \mathrm{MV}$ lines,

- $\quad$ PS-EST is a $132 \mathrm{kV} / 15 \mathrm{kV}$ (HV/MV), it has 2 busbars and $10 \mathrm{MV}$ lines.
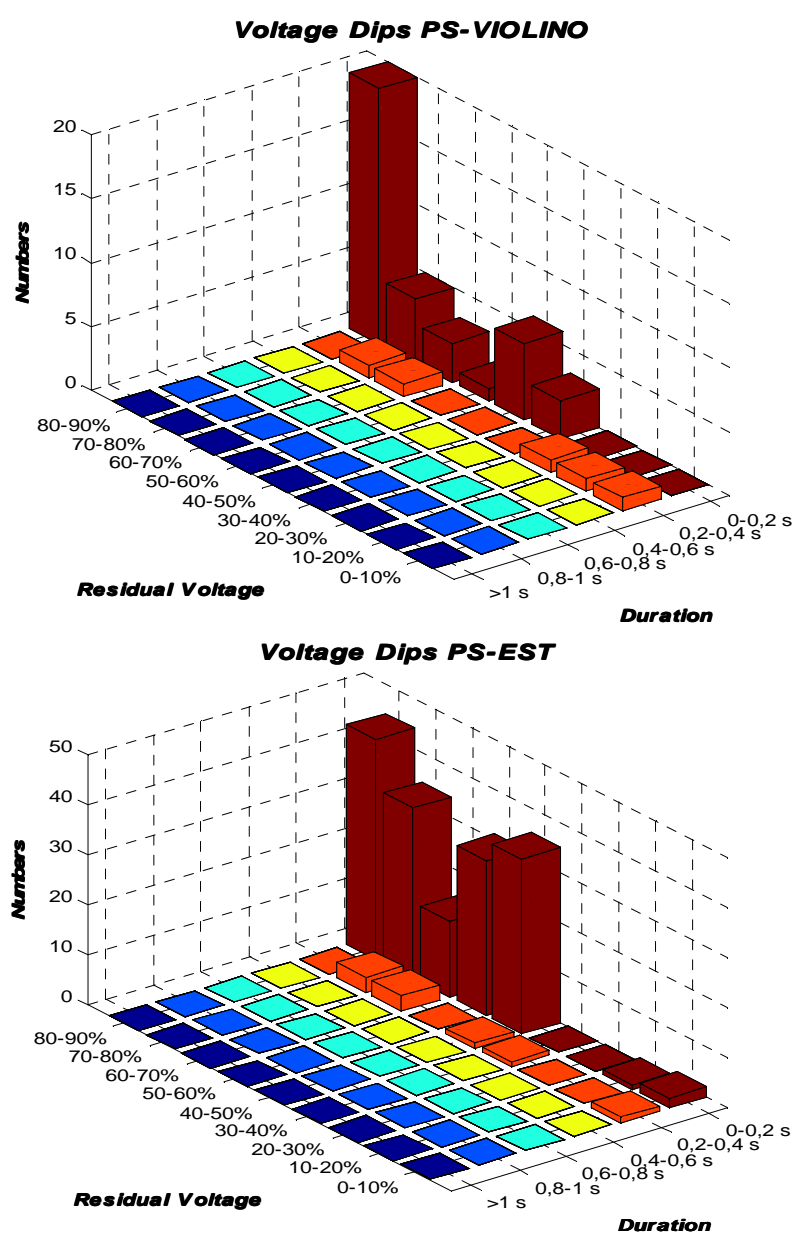

Fig. 5. Distribution of voltage dips for primary substations: (top - 5.a) PS-VIOLINO; (bottom - 5.b) PS-EST.

Table III. Number of event for two primary substations.

\begin{tabular}{l|c|c}
\hline \multicolumn{1}{c|}{ Type of dip } & PS-Violino & PS-Est \\
\hline single phase & 22 & 52 \\
\hline double phase & 9 & 17 \\
\hline three phase & 12 & 102 \\
\hline \multicolumn{1}{c|}{ TOT } & 43 & 171 \\
\hline
\end{tabular}

In PS-EST, the number of deep voltage dips is higher than PS-VIOLINO. Those two examples prove that in 
general, the distribution of voltage dips varies according to the area considered. Together with MV busbars in PS, LV busbars in some secondary substation have been monitored. In the following, two examples will be shown. Fig. 6 and Table IV show data from SS-1056 and SS-1249 that are fed respectively by PS-VIOLINO and PS-EST.
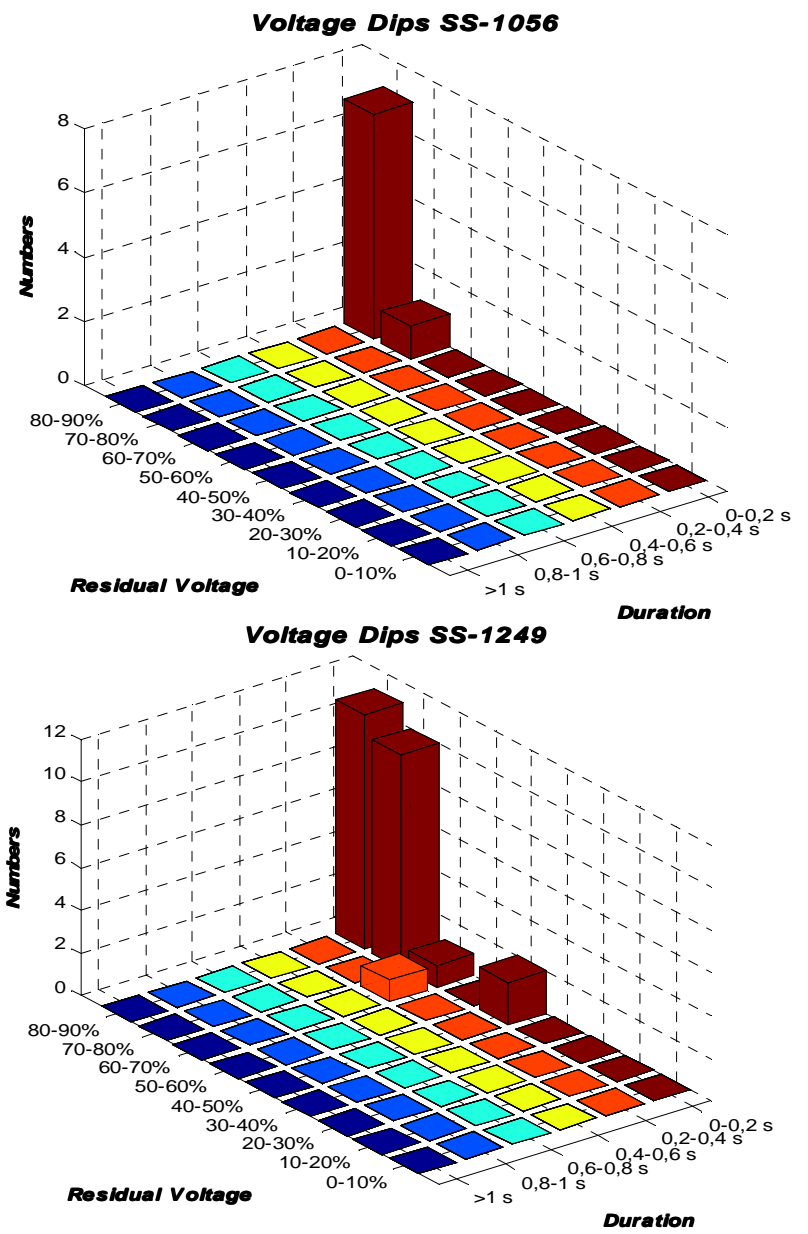

Fig. 6. Distribution of voltage dips for primary substations: (top 6.a) SS-1056; (bottom - 6.b) SS-1249.

Table IV. Number of event for two secondary substations.

\begin{tabular}{l|c|c}
\hline \multicolumn{1}{c|}{ Type of dip } & SS-1056 & SS-1249 \\
\hline single phase & 6 & 14 \\
\hline double phase & 2 & 3 \\
\hline three phase & 0 & 8 \\
\hline \multicolumn{1}{c}{ TOT } & 8 & 25 \\
\hline
\end{tabular}

\section{Analysis of the load distribution}

A general overview of the distribution of the load for the city of Brescia is provided in Fig. 7, which depict the energy delivered per year in GWh as a function of the contractual power of LV customers. In Italy, domestic customers are usually below $6 \mathrm{~kW}$. In 2011 in Brescia, the energy delivered in the cluster $3 \mathrm{~kW}-6 \mathrm{~kW}$ was the $54 \%$ of the energy delivered under $55 \mathrm{~kW} \mathrm{LV}$ contractual power. To size // O-UPQC is important to observe the load profile of end users. In Fig.8 is reported daily mean of domestic customers' load profile for example in July 2011. This is therefore, the group of customers to take into account for the sizing of the system. Fig. 8 reports the daily mean of domestic customers' load profile, in July
2011.

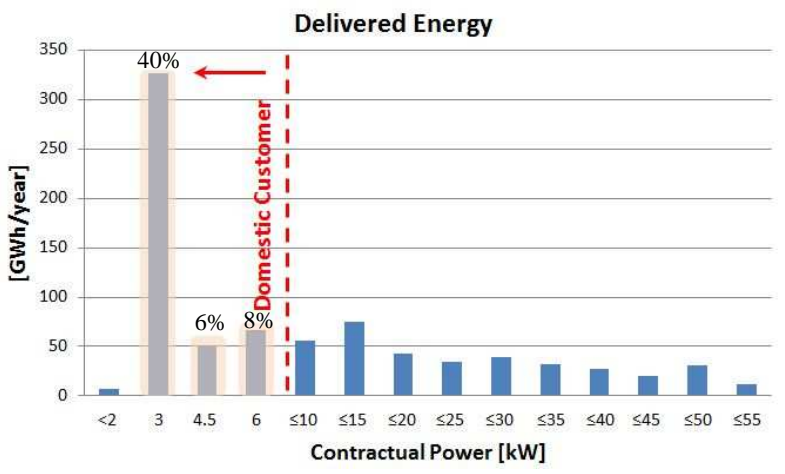

Fig. 7. Delivered energy per year as a function of power peak consumption of LV customers.

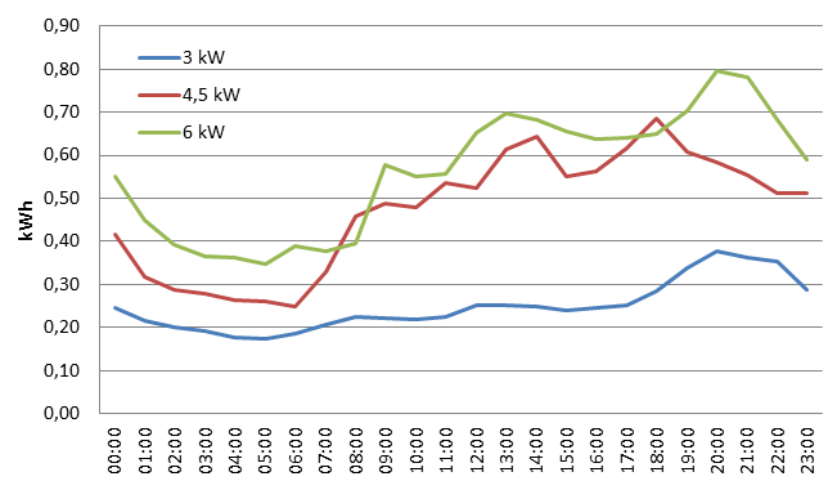

Fig. 8. Daily mean of domestic customer's load profile - July 2011

\section{O-UPQC performance and sizing}

This section is focused on understanding the $O-U P Q C$ compensation limits related to its sizing. The following analysis will be carried out under steady state conditions, defining the normal operation mode when the voltage is inside of the following range $0.9 \cdot V_{n} \leq V_{s} \leq 1.1 \cdot V_{n}$.

It is important to underline that the power absorbed by the loads and the //O-UPQC (shunt) units influences the performance of the $\Sigma O-U P Q C$ (series) unit, and therefore of the whole $O-U P Q C$. Therefore, when considering a particular set of load conditions, it is possible to find operating conditions for the //O-UPQC units that increase the compensating limits of the $\Sigma O-U P Q C$. Depending on whether or not storage systems and interruptible loads are present, the series, the shunt units and loads can exchange only non-active power or both non-active power and active power with the mains. Surely, when the supply voltage $V_{s}$ is near the contractual limits (normal operation mode) the series converter must exchange only non-active power. In order to avoid active power injections, the series voltage $V_{x}$ has to be in quadrature with the mains current $I_{s}$. The $V_{x}$ value is reported in (1), and the grey areas in Fig. 9 indicate the field of possible $V_{x}$ values.

$\bar{V}_{x}=\bar{V}_{P C C} \cdot \frac{\sin \left(\left|\varphi_{P C C}-\varphi_{S}\right|\right)}{\cos \left(\varphi_{S}\right)}$

Another important aspect to underline is that the current $I_{s}$ 
is primarily composed of the current of unprotected loads $U_{2}$ (Fig. 2 - whose phase difference with respect to $V_{P C C}$ cannot be varied) and the current of protected loads $U_{1}$ (Fig. 2 - whose phase difference with respect to $V_{P C C}$ can be changed by the shunt units) as reported in (2), where $P_{U 1,2}$ and $Q_{U 1,2}$ are the active and reactive power of the equivalent load $U_{1,2}$, respectively, $P_{\text {losses }}$ and $Q_{\text {losses }}$ are the active and reactive power lines losses, respectively, and $Q_{b}$ is the reactive power injected by all the shunt units.

$$
\underline{I}_{s}=\frac{P_{U 1}+P_{U 2}+P_{\text {losses }}+j \cdot\left(Q_{U 1}+Q_{b}+Q_{U 2}+Q_{\text {losses }}\right)}{\bar{V}_{P C C}}
$$

Therefore, the angle $\varphi_{P C C}$ can oscillate between the upper and lower limits $\varphi_{P C C_{-} \max }$ and $\varphi_{P C C_{-} \min }$, obtained when $Q_{b}=A_{1}$ and $Q_{b}=-A_{1}$ respectively, in the area highlighted in Fig. $9\left(A_{1}\right.$ is the size of // $\left.O-U P Q C\right)$. Therefore, the current phasor $I_{s}$ can move along the black dotted line, varying the reactive power $Q_{b}$ of the shunt units.

Assuming that $V_{s_{-} \max }+V_{s_{-} \min } \approx 2 \cdot V_{P C C}$, it is possible to demonstrate that the range amplitude $V_{s_{-} \max }-V_{s_{-} \min }$ can be obtained with equation (3).

$$
V_{s_{-} \max }-V_{s_{-} \min } \approx 2 \cdot V_{x_{-} \max } \cdot \sin \left(\varphi_{P C C_{-} \max }\right)
$$

It can be seen that the compensating range amplitude $V_{s_{-} \max }-V_{s_{-} \min }$ depends on the $V_{x_{-} \max }$ value that the series unit can inject, and on the non-active power $Q_{b}$.

When the shunt units can exchange active and non-active power with the mains (than in the eq. 1 appears the $P_{b}$ term), the performance of the $O-U P Q C$ does not change a lot. Figure 9 depicts the new phasor diagram of the $O-U P Q C$ under the above operating conditions.

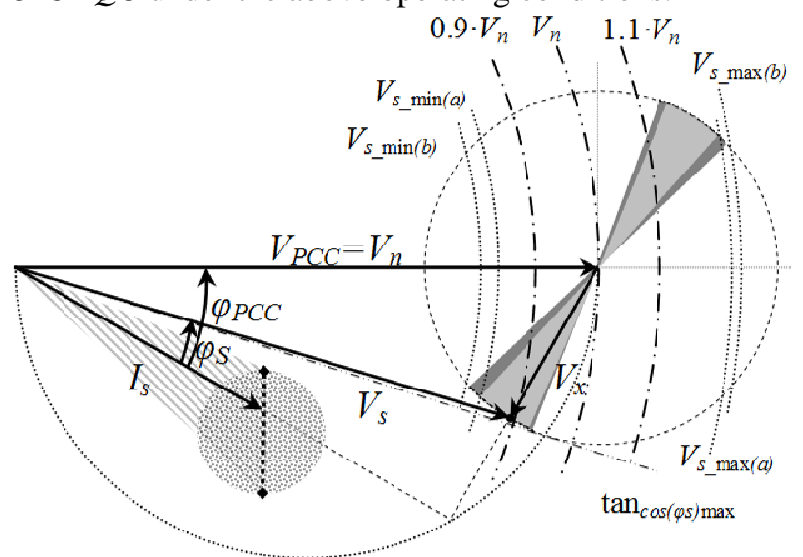

Fig. 9. Compensation limits of the $O-U P Q C$ : with non-active power exchange only (light grey) and with also active power exchange (dark grey) by the shunt units

In Fig. 9, the light grey areas indicate the field in which $V_{x}$ can lay without active power exchanges by the shunt units, and the dark grey areas indicate the new possible values of $V_{x}$ with active power exchanges by shunt units. In this case, the compensating range amplitude $V_{s_{-} \max }-V_{s_{-} \min }$ is greater than without active power exchanges, but it is important to note that the difference is very small. The phasor current $I_{s}$ can move inside of the grey dotted circle, varying the active and non-active power of the shunt units (movement on the black dotted line regards only non-active power exchange). Therefore the loads can manage the active power without constrains. This condition could be represented as an active network into which dispersed generations are inserted. When the network is outside from the normal operation mode both series and shunt units inject active power. Given a storage system it is possible to compensate voltage disturbances in $V_{s}$ that are outside of the contractual limits. At the same time in case of mains interruptions the SS of the shunt units switch off, and the loads are supplied in back-up mode.

Considering compensation of transient disturbances, such as voltage dips, swells, etc., various compensation strategies are available for the $O-U P Q C$, including minimizing the energy required by the storage system of the series unit. The new phasor diagram of the $O-U P Q C$ operation is shown in Fig. 10. In the case of transient disturbances, the series unit can compensate the voltage $V_{s}$ over a very large range compared with all the cases previously analysed. Indeed, the series unit can exchange active power with the mains in the dark grey areas, but this is only possible for transient disturbances due to the small size of the series unit storage system.

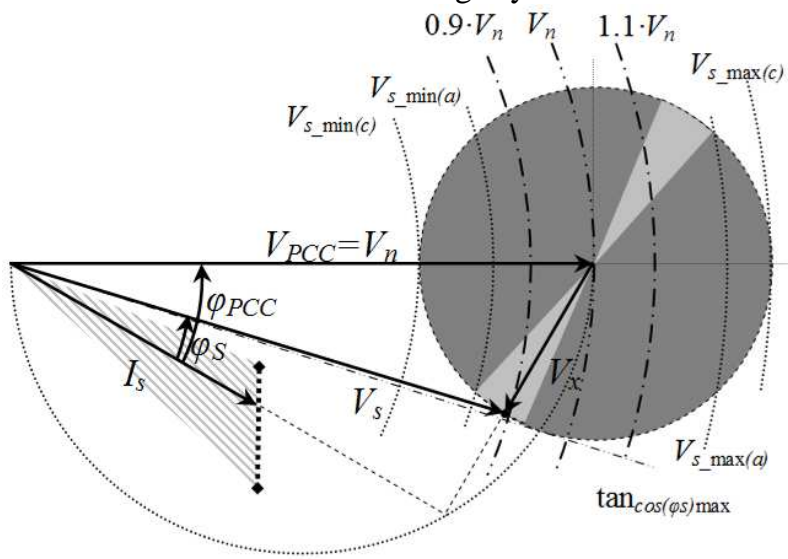

Fig. 10. Compensation limits of the OPEN UPQC: with non-active power exchange only (light grey) and with also active power exchange (dark grey) by the series unit

As introduced in the previous part, in order to operate correctly, the $O-U P Q C$ has to be determined in each elements. These parameters depending for the series unit from the load of network supplied and for the shunt unit from the load and autonomy of the single final customer supplied. Therefore, considering that in our test, the $\Sigma O-U P Q C$ unit will be directly connected downstream to the $\mathrm{MV} / \mathrm{LV}$ transformer of the secondary substation SS-1056, a nominal voltage of about $25 \%$ is more than enough to compensate all the voltage dips measured in this secondary substation, see Fig. 6.a. So doing the nominal power of the $\Sigma O-U P Q C$ unit can be of $100 \mathrm{kVA}$ to compensate all these kind of voltage dips at maximum supplied current. To exchange active power with the mains, a storage system connected to the DC section of the series unit is needed. The storage system size does not need to be very large, because little energy is required to compensate these disturbances. To compensate the voltage variations for 30 cycle for the maximum load condition $(400 \mathrm{~kW})$, an energy equal to $60 \mathrm{~kJ}$ is needed, 
corresponding to a battery capacity of about $0.4 \mathrm{Ah}$ at $48 \mathrm{~V}$ or a capacitor or supercapacitor bank of about $0.8 \mathrm{~F}$ at $400 \mathrm{~V}$ [9]-[11]. This value can be double in order to allow bidirectional energy exchange with the mains.

The //O-UPQC unit sized is function of connection typology of the customer (mono-phase or three-phase), the nominal power and the autonomy required. Therefore several power sizes have to be available to satisfy customer needs. Considering the delivered energy of LV customers reported in Fig. 7, it is possible to define two main size for this unit, the first one of $2 \mathrm{~kW}$ and the second one of $4 \mathrm{~kW}$. Depending on the customer these size are good to obtain: from one side, important economic saving (reducing the tariff profile) especially for all the customers with a nominal power of $4.5 \mathrm{~kW}$ and $6 \mathrm{~kW}$; while from another side, power quality improvement reducing power peak absorption and back-up. It is important to underline that the transient current sizing of the //O-UPQC unit has to be at least double of the nominal value required in order to manage correctly the protection apparatus of the customer. To compensate the load absorption for 1 hour for an average load of $0.6 \mathrm{~kW}$ (Fig. 8), an energy equal to $2160 \mathrm{~kJ}$ is needed, corresponding to a battery capacity of about $25 \mathrm{Ah}$ at $24 \mathrm{~V}$.

It is necessary to underline that the control strategy of the // O-UPQC unit have to be made in order to filter harmonic component reducing residual ripple current in line. Therefore the values of LCL output filter of the series unit has to assure that the maximum voltage output value required to VSI to compensate the load current and provide all the active power has not to exceed the nominal DC voltage value (for mono-phase application of 500V).

An additional important aspect is to evaluate the maximum value of reactive power injectable by all the //O-UPQC units $\left(Q_{b}\right)$ in normal operation mode. Supposing a // $O-U P Q C$ unit at home of about $50 \%$ of $3 \mathrm{~kW}$ customers and of all the $4,5 \mathrm{~kW}$ and $6 \mathrm{~kW}$ customers, the maximum reactive power injectable is equal to about the reactive power absorbed by all the end users of the LV grid in exam. This permits to adopt several compensations strategy.

\section{Conclusion}

PQ monitor and regulation is becoming more and more important as the penetration level of renewable sources is increasing. In the future new solutions have to be found on the power grid, to cope with the regulation. The paper first of all introduce data collected in the city of Brescia, where PQ analysers have been installed in every primary substation and in some secondary substations. The load distribution analysis shows that the most part of the energy (more than 50\%) is absorbed by domestic customers with a contractual power typically in the range of $3-6 \mathrm{~kW}$. These kind of customer actually are not involved in network stability problems. Therefore in the Smart Domo Grid (SDG) project we focus mainly on these users trying to solve problems of quality of voltage supply of the LV network using an innovative distributed electronic power system called $O-U P Q C$.

Dips voltage analysis shows that the events measured in primary substation are reflected only in part on the secondary substation and that the most of them has a short duration and a depth. During the course of SDG project we will want to demonstrate that the $\Sigma O-U P Q C$ system, sizing for 1056 secondary substation, can compensate voltage dips and in function of the number of distributed // $O-U P Q C$ installed in the home of the domestic end users can be able to cope with the totality of detected events, and then provide to the end user a quality of voltage supply much higher.

\section{References}

[1] AEEG, "ARG/elt 198/11 - Testo integrato della regolazione della qualità dei servizi di distribuzione, misura e vendita dell'energia elettrica per il periodo di regolazione 2012-2015" [Online]. Available: www.autorita.energia.it/it/docs/11/198-11 arg.htm

[2] European Commission. "Towards a new Energy Strategy for Europe 2011-2020". ec.europa.eu/energy/strategies/consultations/doc/2010_07 _02/2010_07_02_energy_strategy.pdf

[3] R. Faranda, R. Argiento, A. Pievatolo, E. Tironi: Distributed Interruptible Load Shedding and MicroGenerator Dispatching to Benefit System Operations, IEEE Transaction on Power Sytems, vol. PP, Issue 99, November 2011, pp. 1-9, ISSN 0885-8950.

[4] R. Faranda, E. Tironi, I. Valadè, D. Zaninelli, Power Quality Improvement Using Series Electronic Reactor and Shunt Power Conditioner, International Symposium and Exhibition on Electric Power Engineering at the beginning of the Third Millennium, Capri (Napoli), 12-18 May 2000.

[5] A. Agustoni, E. Borioli, M. Brenna, G. Simioli, E. Tironi, G. Ubezio, LV DC distribution network with distributed energy resources: analysis of possible structures, 18th International Conference on Electricity Distribution CIRED 2005, Turin, Italy, 6-9 June 2005.

[6] M. Brenna, R. Faranda, E. Tironi, OPEN UPQC able to improve power quality of network and loads, International Congress on Electricity Distribution CIDEL Argentina 2006, Buenos Aires, Argentina, 27-29 November 2006.

[7] R. Faranda, M. Brenna, E. Tironi, A new proposal for Power Quality and Custom Power: OPEN UPQC, IEEE Transaction on Power Delivery, vol. 24, n. 4, October 2009, pp. 2107-2116, ISSN 0885-8977.

[8] R. Faranda, F. Castelli Dezza, I. Mazzucco, P. Redi, E. Tironi, An interface converter for DG/storage system able to improve Power Quality of the load, IEEE Power Engineering Society PES, Montreal, Canada, 18-22 June, 2006.

[9] R. Faranda, A new parameters identification procedure for simplified double layer capacitor two-branch model, Elsevier Electric Power Systems Research, Volume 80, Issue 4, April 2010, Pages 363-371, ISSN: 0378-7796.

[10] R. Faranda, M. Gallina, D.T. Son, A new simplified model of Double-Layer Capacitors, International Conference on Clean Electrical Power ICCEP, 21-23 maggio 2007

[11] R. Faranda, S. Leva, V. Musolino, L. Piegari, Energy Storage, Energy Science and Technology, Nova Science Publishers Inc., ISBN 978-161324-708-2.

[12] M. Buschmann, G. Linhofer, P. Maibach, O. Suter, Voltage Source Converter based Power Quality Solutions, Asia Pacific Regional Power Quality Seminar, 28-31 March 2005, Marriot Putrajaya, Malaysia 